\title{
Cancer mortality in a cohort of asbestos textile workers
}

\author{
E Pira', C Pelucchi, ${ }^{*, 2}$ L Buffoni', A Palmas', M Turbiglio', E Negri², PG Piolatto' and C La Vecchia ${ }^{2,3}$ \\ 'Dipartimento di Traumatologia, Ortopedia e Medicina del Lavoro, Università degli Studi di Torino, via Zuretti 29, 10126 Torino, Italy; ${ }^{2}$ stituto di Ricerche \\ Farmacologiche 'Mario Negri', via Eritrea 62, 20157 Milano, Italy; ${ }^{3}$ Istituto di Statistica Medica e Biometria, Università degli Studi di Milano, via Venezian \\ I, 20133 Milano, Italy
}

A cohort of 889 men and 1077 women employed for at least I month between 1946 and 1984 by a former Italian leading asbestos (mainly textile) company, characterised by extremely heavy exposures often for short durations, was followed up to 1996, for a total of 53024 person-years of observation. Employment data were obtained from factory personnel records, while vital status and causes of death were ascertained through municipality registers and local health units. We observed 222 cancer deaths compared with I I6.4 expected (standardized mortality ratio, $S M R=191$ ). The highest ratios were found for pleural $(S M R=4 \mid 05)$, peritoneal $(S M R=1817)$ and lung $(S M R=282)$ cancers. We observed direct relationships with duration of employment for lung and peritoneal cancer, and with time since first employment for lung cancer and mesothelioma. Pleural cancer risk was independent from duration $(S M R=3428$ for employment $<1$ year, 7659 for $1-4$ years, 2979 for $5-9$ years and 2130 for $\geqslant 10$ years). Corresponding SMRs for lung cancer were 139, 25I, 233 and 531. Nonsignificantly increased ratios were found for ovarian (SMR=26I), laryngeal $(\mathrm{SMR}=238)$ and oro-pharyngeal $(\mathrm{SMR}=226)$ cancers. This study confirms and further quantifies the central role of latency in pleural mesothelioma and of cumulative exposure in lung cancer.

British Journal of Cancer (2005) 92, 580-586. doi:I0.1038/sj.bjc.6602240 www.bjcancer.com

(c) 2005 Cancer Research UK

Keywords: asbestos; cancer mortality; cohort study; lung cancer; mesothelioma

Cohort studies found increased incidence and mortality from mesothelioma among (chiefly male) asbestos workers employed in mining (Piolatto et al, 1990; McDonald et al, 1993), but mainly textile and manufacture (Newhouse and Berry, 1979; Berry et al, 2000; Yano et al, 2001), insulation (Selikoff et al, 1979) and asbestos-cement factories (Tulchinsky et al, 1999; Ulvestad et al, 2002). Mesothelioma risk varied widely among different studies, according to types of asbestos involved (chrysotile, amosite or crocidolite) (Hodgson and Darnton, 2000) and levels of exposure (Doll and Peto, 1985). Since other factors such as duration and years since first and last asbestos exposure (Bianchi et al, 1997; Hauptmann et al, 2002) also determine mesothelioma risk, it is important to analyse all these factors to disentangle their separate effects. This could also help to understand the recent levelling off of mesothelioma trends in some European countries (Peto et al, 1999; Hemminki and Li, 2003; Montanaro et al, 2003; Pelucchi et al, 2004).

Asbestos is a major cause of lung cancer too, acting multiplicatively with tobacco smoking (Saracci, 1977; Vainio and Boffetta, 1994). A meta-analysis of 69 cohort studies found a standardized mortality ratio (SMR) of 163 for lung cancer, with a substantial heterogeneity (Goodman et al, 1999) largely attributable to the different cumulative exposure to asbestos in various cohorts, this being the major determinant of lung cancer risk

* Correspondence: C Pelucchi, ScD, Istituto di Ricerche Farmacologiche 'Mario Negri', Via Eritrea, 62-20I57 Milano, Italy;

E-mail: pelucchi@marionegri.it

Received 13 July 2004; revised 29 September 2004; accepted 29 September 2004
(Boffetta, 1998). Chrysotile fibres are considered less carcinogenic than amphiboles and it has been estimated that cohorts exposed to amosite and crocidolite experience an excess of lung cancer in the exposure specific risk of around $5 \%$ per $\mathrm{ff} \mathrm{ml}^{-1}$ year, while the corresponding risk for chrysotile alone is between 0.1 and $0.5 \%$ (Hodgson and Darnton, 2000).

To further investigate these issues, we have analysed data from a cohort including about 900 men and more than 1000 women from an Italian company. Sited in Grugliasco, near Turin, the company produced various asbestos-containing, particularly textile, goods.

\section{MATERIALS AND METHODS}

Subjects included in the cohort were 1973 men and women who had worked in a major asbestos textile manufacture for at least 1 month in the period from 1946 to 1984, when production was dismissed. Seven subjects $(0.4 \%)$ lacked information on date of birth or date of death and were thus excluded from the analysis, leaving 1966 subjects (889 males and 1077 females) who were followed up to 31 December 1996 or until reaching 80 years of age, if this occurred earlier. Overall, 1333 (67.8\%) subjects survived the follow-up period, $545(27.7 \%)$ died and $88(4.5 \%)$ emigrated or were lost to follow-up for other reasons. Subjects lost to follow-up were included in the analysis, considering the last information available as end point. A total of 53024 person-years of observation (22 332 man-years and 30692 woman-years) were covered.

Employment data were obtained from personnel records at the factory, while vital status and causes of death were ascertained through registers from municipal offices and local health units. Information was available on date and place of birth, migration(s) 
and death, on cause of death and on periods and duties of employment(s). Cases of mesothelioma were further checked matching them up to regional mesothelioma registers.

We computed the expected numbers of deaths from all causes and from selected cancer sites using national death rates for each 5 -year calendar period and age group. National death rates for each cause and quinquennium of age were available from 1955 and were taken from the Central Institute of Statistics (ISTAT, 19551996). We therefore applied the 1955-1959 death rates also to periods 1946-1949 and 1950-1954. SMR were computed for the overall study population as well as according to duration, time since first and last employment and age at first employment, separately for men and women (Breslow and Day, 1987).

Only the date of death, and not the date of diagnosis, was available to us. As retirement or change of job may in some cases have been due to the diseases themselves, deaths that occurred within 3 years of stopping exposure were considered together with those during exposure.

Two general models were considered for the mesothelioma death rates in workers exposed to asbestos (Breslow et al, 1983). These were, first, the multiplicative (or relative risk) model:

$O_{(k)}=E_{(k)} \mathrm{e}^{\beta^{\prime} Z(k)}$

where $O_{(k)}$ is the observed number of mesothelioma deaths in the $k$ th category, $E_{(k)}$ is the expected number of deaths in the $k$ th category based on national mortality rates, $Z_{(k)}$ is a vector of covariates (such as age at first exposure, duration, etc) whose influence on the event is being examined, and $\beta^{\prime}$ is a vector of unknown parameters, to be estimated. In this model, the effect of each factor acts multiplicatively on the expected rate in the general population.

The second general model considered was the additive (or excess risk) model:

$O_{(k)}=E_{(k)}+P Y_{(k)} \mathrm{e}^{\beta^{\prime} Z(k)}$

with variables defined as above, and $P Y_{(k)}$ defined as the total number of person-years in the category $K$. In this model, each factor is assumed to act multiplicatively on the excess risk, and the resulting product then adds to the expected number in the general population. To fit the two equations, we used the GLIM package (Baker and Nelder, 1978).

Various types of asbestos were used in the factory, including crocidolite. To estimate levels of asbestos exposure, environmental sampling was carried out (Scansetti et al, 1985) as follows: static samples were taken between 1973 and 1978/9, using mercury clepsydra vacuum pump ('Zurlo') with mixed-cellulose ester filters (MCE), Micropore, $20 \mathrm{~mm}$ diameter (diameter filter efficacy $6 \mathrm{~mm}$ ) and $0.8 \mu \mathrm{m}$ porosity at a capturing speed of $1.2 \mathrm{~m} \mathrm{~s}^{-1}$. Sampling time was from 15 to $20-25 \mathrm{~min}$ for a volume of air from 1 to $2 \mathrm{l}$. Personal samples were taken from 1978 using the 'Du Pont alpha 1 model' and 'Zambelli Ego model' constant flow instrumentation. A 40-mm long cylinder-shaped spacer was used together with MCE, Micropore, $25 \mathrm{~mm}$ in diameter and porosity of $0.8 \mu \mathrm{m}$. Flow rate was $21 \mathrm{~min}^{-1}$ for $30-50 \mathrm{~min}$.

The MCE filters were cleared, in both cases, using acetone vapours with a few drops of Triacetin (Glycerol Triacetate) to spread fibres evenly on the filter. Phase contrast optical microscopy $(\times 500)$ was used to count the fibres. Only respirable fibres were counted using a Walton-Beckett graticulate. Respirable fibres were defined as diameter $\leqslant 3 \mu \mathrm{m}$; length $\geqslant 5 \mu \mathrm{m}$; aspect-ratio (length-diameter relationship) at least $3: 1$, and UICC standards were used for crysothile, crocidolite, amosite and anthophyllite asbestos.

\section{RESULTS}

Table 1 gives observed number of deaths and the SMRs for several cancer sites, separately for men and women. Overall, we observed 222 cancer deaths compared with 116.4 expected (SMR $=190.7)$. The highest ratios were observed for pleural $(S M R=4105.5)$ and peritoneal cancers $(S M R=1817.2)$. Excess ratios were found also

Table I Observed mortality and standardized mortality ratios (SMR), with 95\% confidence intervals (CI), of selected cancers

\begin{tabular}{|c|c|c|c|c|c|c|c|}
\hline \multirow[b]{2}{*}{ Cause of death (ICD-IX) } & \multicolumn{2}{|c|}{ Males } & \multicolumn{2}{|c|}{ Females } & \multicolumn{3}{|c|}{ Total } \\
\hline & Obs & SMR & Obs & SMR & Obs & SMR & $95 \% \mathrm{Cl}$ \\
\hline Oral and pharyngeal (140-149) & 7 & $253.9^{a}$ & 0 & 0 & 7 & 225.6 & $90-465$ \\
\hline Stomach $(|5|)$ & | | & $1 \mid 5.9$ & 4 & 134.3 & 15 & 120.3 & $67-198$ \\
\hline Colorectal (|52-|54||59.0) & 10 & 139.2 & 6 & |56.| & 16 & $|45|$. & $83-235$ \\
\hline Liver $(155)$ & 6 & 225.7 & 0 & 0 & 6 & 177.9 & $65-388$ \\
\hline Peritoneum (158) & 5 & $1090.3^{\mathrm{a}}$ & 9 & $2886.5^{\mathrm{a}}$ & 14 & $1817.2^{\mathrm{a}}$ & $992-3053$ \\
\hline Larynx (I6I) & 7 & 245.8 & 0 & 0 & 7 & 238.0 & $95-490$ \\
\hline Lung (162) & 62 & $252.4^{\mathrm{a}}$ & 14 & $595.6^{a}$ & 76 & $282.4^{\mathrm{a}}$ & $222-354$ \\
\hline Pleura (163) & 12 & $2851.5^{\mathrm{a}}$ & | | & $7891.2^{\mathrm{a}}$ & 23 & $4105.5^{\mathrm{a}}$ & $2603-6158$ \\
\hline Breast (174) & 0 & 0 & 7 & 82.2 & 7 & 81.5 & $33-168$ \\
\hline Ovary (183) & - & - & 5 & 261.4 & 5 & 261.4 & $85-609$ \\
\hline Prostate (185) & 2 & 60.4 & - & - & 2 & 60.4 & $7-218$ \\
\hline Bladder (I 88) & 3 & 93.5 & 0 & 0 & 3 & 85.3 & $18-249$ \\
\hline Kidney (189) & 0 & 0 & 2 & 424.1 & 2 & 98.0 & $12-354$ \\
\hline Brain $(|9|-\mid 92)$ & 4 & 150.0 & I & 61.6 & 5 & 116.6 & $38-272$ \\
\hline Pleura+peritoneum & 17 & $1933.1^{\mathrm{a}}$ & 20 & $4432.6^{a}$ & 37 & $2780.7^{\mathrm{a}}$ & $1958-3833$ \\
\hline All cancers $(140-239)$ & 148 & $184.5^{\mathrm{a}}$ & 74 & $204.6^{a}$ & 222 & $190.7^{\mathrm{a}}$ & $166-218$ \\
\hline Asbestosis (50I) & 27 & - & | | & - & 38 & - & - \\
\hline All causes & 377 & $154.0^{\mathrm{a}}$ & 168 & $178.2^{\mathrm{a}}$ & 545 & $160.7^{\mathrm{a}}$ & $147-175$ \\
\hline Total no. of subjects & 889 & & 1077 & & 1966 & & \\
\hline Person-years & 22332 & & 30692 & & 53024 & & \\
\hline
\end{tabular}

a95\% confidence interval does not include 100. 
for lung, ovarian, laryngeal and oro-pharyngeal cancers. The SMR for all neoplasms were 204.6 for women and 184.5 for men. For pleural, peritoneal and lung cancer the SMR was higher in women, while no female deaths were observed for oral, pharyngeal and laryngeal cancers. There were 38 deaths attributable to asbestosis. The SMR for pleural cancer is probably overestimated, since national mortality rates were used to compute expected deaths. In the mid-1970s the province of Turin had, compared with the whole of Italy, SMR for pleural cancer of 187 for males and 191 for females. Correcting for these ratios, the SMR for pleural cancer would be about 2200 . On the other hand, for most cancer sites of interest, Turin rates did not differ importantly from Italian ones. In fact, the SMR for all neoplasms for the province of Turin as compared to Italy was 109 for males and 114 for females (Cislaghi et al, 1986).

Cancers of the respiratory and digestive tracts and of the ovary are considered, for men and women combined, in Table 2 in relation to duration of employment. For total cancer mortality and for mortality overall, the SMR increased with duration of employment. For lung cancer, the SMR rose from 139.1 for exposures $<1$ year to 530.9 for exposures $\geqslant 10$ years. A direct relationship was observed also for peritoneal (the highest SMR was 4298.0 for employment $\geqslant 10$ years), but not for pleural and gastrointestinal cancers. The SMR for pleural cancer was 3427.7 for $<1$ year of exposure, 7659.3 for 1 to $<5$ years, 2978.6 for 5 to $<10$ years and 2129.9 for $\geqslant 10$ years.

Corresponding figures with relation to time since first employment are given in Table 3. The SMR for all causes of death increased with time since first employment. For all neoplasms combined, the SMR was 79.6 for $<15$ years since first exposure, 217.3 for 15 to $<25,245.8$ for 25 to $<35$ and 217.2 for $\geqslant 35$ years. Between 15 and 25 years since first employment, the SMR were 1599.4 for peritoneal cancer and 2910.2 for pleural and peritoneal mesothelioma combined; corresponding values increased to 2062.9 and 3593.0 for latency of 25 to $<35$ years, and to 5360.6 and 4480.7 for latency $\geqslant 35$ years. There were 12 deaths from pleural cancer 25 years or more after first employment, while 0.3 were expected.

Time since last exposure is considered in Table 4. No significant excess in overall mortality $(\mathrm{SMR}=103.3)$ nor in cancer mortality

Table 2 Observed mortality and standardized mortality ratios (SMR) of selected cancers, according to duration of employment (years)

\begin{tabular}{|c|c|c|c|c|c|c|c|c|}
\hline \multirow[b]{2}{*}{ Cause of death } & \multicolumn{2}{|c|}{$<\mathbf{I}$} & \multicolumn{2}{|c|}{ I to $<5$} & \multicolumn{2}{|c|}{5 to $<10$} & \multicolumn{2}{|c|}{$\geqslant 10$} \\
\hline & Obs & SMR & Obs & SMR & Obs & SMR & Obs & SMR \\
\hline Stomach cancer & 5 & 142.4 & 2 & 62.6 & 6 & 263.6 & 2 & 57.3 \\
\hline Colorectal cancer & 7 & 223.4 & I & 35.2 & 3 & 145.5 & 5 & 167.2 \\
\hline Peritoneal cancer & I & 468.4 & 1 & 494.8 & 3 & $2063.1^{\mathrm{a}}$ & 9 & $4298.0^{\mathrm{a}}$ \\
\hline Laryngeal cancer & I & 105.4 & 3 & 397.9 & 2 & 390.3 & 1 & 137.7 \\
\hline Ovarian cancer & 2 & 440.8 & 0 & 0 & 0 & 0 & 3 & $573.7^{\mathrm{a}}$ \\
\hline Pleural+peritoneal cancers & 7 & $1801.8^{\mathrm{a}}$ & 12 & $3471.2^{\mathrm{a}}$ & 6 & $2437.8^{\mathrm{a}}$ & 12 & $3426.1^{\mathrm{a}}$ \\
\hline All cancers & 51 & $149.0^{a}$ & 50 & $165.7^{\mathrm{a}}$ & 41 & $191.4^{\mathrm{a}}$ & 80 & $261.7^{\mathrm{a}}$ \\
\hline All causes & 136 & $138.6^{\mathrm{a}}$ & 131 & $148.6^{\mathrm{a}}$ & 97 & $156.7^{\mathrm{a}}$ & $|8|$ & $199.1^{\mathrm{a}}$ \\
\hline
\end{tabular}

a $85 \%$ confidence interval does not include 100 .

Table 3 Observed mortality and standardized mortality ratios (SMR) of selected cancers, according to time since first employment (years)

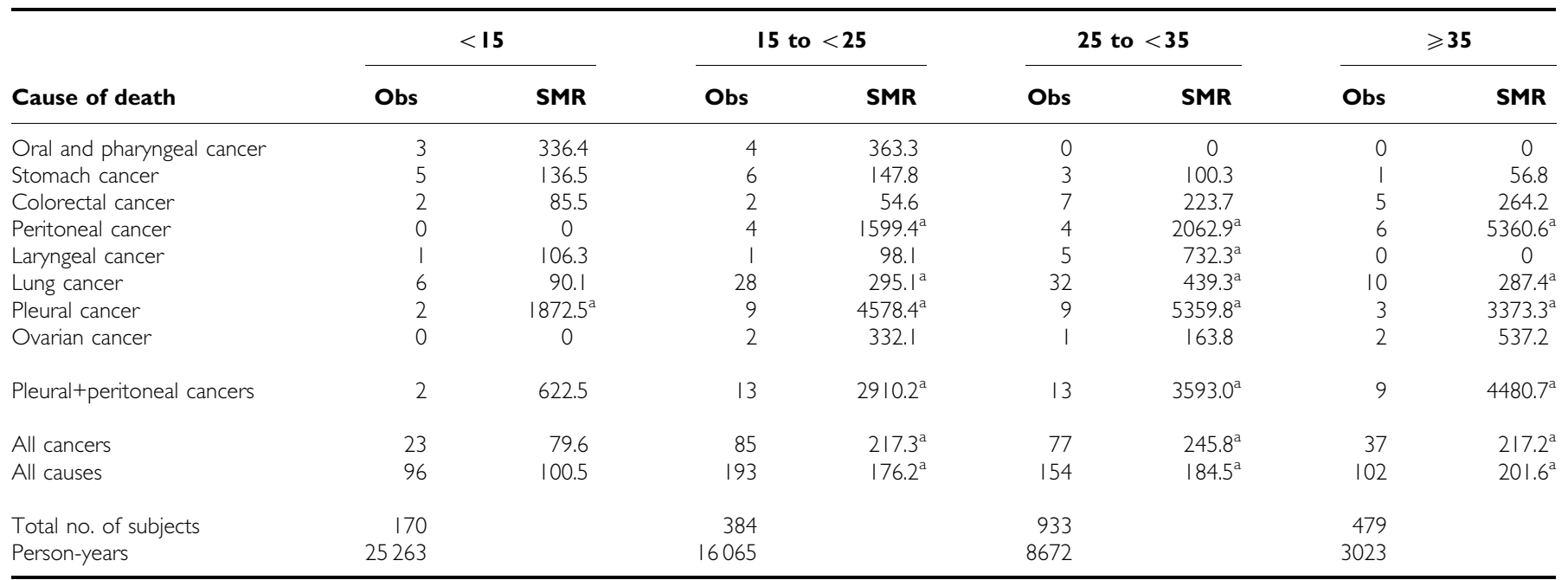

${ }^{\mathrm{a}} 85 \%$ confidence interval does not include 100 . 


\begin{tabular}{|c|c|c|c|c|c|c|c|c|c|c|}
\hline \multirow[b]{2}{*}{ Cause of death } & \multicolumn{2}{|c|}{ During exposure $/<\mathbf{3}$} & \multicolumn{2}{|c|}{3 to $<15$} & \multicolumn{2}{|c|}{ I 5 to $<25$} & \multicolumn{2}{|c|}{25 to $<35$} & \multicolumn{2}{|c|}{$\geqslant 35$} \\
\hline & Obs & SMR & Obs & SMR & Obs & SMR & Obs & SMR & Obs & SMR \\
\hline Oral and pharyngeal cancer & 1 & 186.4 & 2 & 178.9 & 4 & $472.0^{\mathrm{a}}$ & 0 & 0 & 0 & 0 \\
\hline Stomach cancer & 2 & 86.8 & 6 & 128.6 & 4 & 120.9 & 2 & 119.9 & । & 189.7 \\
\hline Colorectal cancer & 0 & 0 & 5 & 134.4 & 6 & 183.2 & 3 & 151.7 & 2 & 291.0 \\
\hline Peritoneal cancer & 1 & 736.9 & 2 & 728.1 & 10 & $4791.6^{\mathrm{a}}$ & 0 & 0 & 1 & 2785.5 \\
\hline Laryngeal cancer & 0 & 0 & 3 & 271.3 & 2 & 266.6 & 2 & 498.5 & 0 & 0 \\
\hline Lung cancer & 7 & 183.2 & 30 & $309.3^{\mathrm{a}}$ & 26 & $351.9^{a}$ & 11 & $242.3^{\mathrm{a}}$ & 2 & 136.5 \\
\hline Pleural cancer & 1 & $1733 . \mid$ & 5 & $2718.9^{a}$ & 8 & $4670.2^{\mathrm{a}}$ & 8 & $7252.9^{a}$ & I & 2702.7 \\
\hline Ovarian cancer & I & 415.5 & 2 & 366.0 & I & 172.3 & 0 & 0 & i & 747.9 \\
\hline Pleural+peritoneal cancers & 2 & $1034.1^{\mathrm{a}}$ & 7 & $1526.4^{\mathrm{a}}$ & 18 & $4736.8^{a}$ & 8 & $3547.7^{\mathrm{a}}$ & 2 & $2743.5^{\mathrm{a}}$ \\
\hline All cancers & 19 & 107.3 & 82 & $202.4^{\mathrm{a}}$ & 75 & $230.3^{\mathrm{a}}$ & 34 & $176.2^{\mathrm{a}}$ & 12 & 190.4 \\
\hline All causes & 60 & 103.3 & 206 & $169.8^{\mathrm{a}}$ & 168 & $179.3^{\mathrm{a}}$ & 85 & $171.6^{\mathrm{a}}$ & 26 & $158.1^{\mathrm{a}}$ \\
\hline Total no. of subjects & 139 & & 395 & & 510 & & 703 & & 219 & \\
\hline Person-years & 14493 & & 20254 & & 12027 & & 5182 & & 1068 & \\
\hline
\end{tabular}

${ }^{\mathrm{a}} 85 \%$ confidence interval does not include 100.

Table 5 Observed mortality and standardized mortality ratios (SMR) of selected cancers, according to age at first exposure (years)

\begin{tabular}{|c|c|c|c|c|c|c|}
\hline \multirow[b]{2}{*}{ Cause of death } & \multicolumn{2}{|c|}{$<25$} & \multicolumn{2}{|c|}{25 to $<35$} & \multicolumn{2}{|c|}{$\geqslant 35$} \\
\hline & Obs & SMR & Obs & SMR & Obs & SMR \\
\hline Stomach cancer & 2 & 131.4 & । & 37.6 & 12 & 144.8 \\
\hline Colorectal cancer & 3 & 163.2 & 2 & 75.3 & 11 & 168.3 \\
\hline Peritoneal cancer & 6 & $4183.8^{\mathrm{a}}$ & 6 & $3072.3^{\mathrm{a}}$ & 2 & 463.3 \\
\hline Laryngeal cancer & I & 383.8 & । & 157.2 & 5 & 244.5 \\
\hline Ovarian cancer & 2 & 275.6 & 2 & 337.2 & 1 & 168.5 \\
\hline Pleural+peritoneal cancers & 12 & $5110.7^{\mathrm{a}}$ & 11 & $3258.3^{\mathrm{a}}$ & 14 & $1846.5^{\mathrm{a}}$ \\
\hline All cancers & 40 & $203.7^{\mathrm{a}}$ & 61 & $216.8^{\mathrm{a}}$ & 121 & $176.3^{\mathrm{a}}$ \\
\hline All causes & 96 & $184.2^{\mathrm{a}}$ & 136 & $175.1^{\mathrm{a}}$ & 313 & $149.5^{\mathrm{a}}$ \\
\hline
\end{tabular}

${ }^{a} 85 \%$ confidence interval does not include 100.

$(\mathrm{SMR}=107.3)$ was reported during employment. However, elevated SMR were observed in almost all subgroups of pleural and peritoneal cancers, peaking at 4736.8 after 15 to $<25$ years since last employment for mesotheliomas.

Table 5 reports SMR for selected cancer sites in subgroups of age at first employment. No evident pattern emerged, the SMR were higher for overall mortality (184.2), peritoneal (4183.8) and pleural cancers (6562.3), and mesothelioma (5110.7) when first employment occurred before 25 years of age, while the SMR were higher for all cancers (216.8) and for lung cancer (408.3) in the subgroup of first employment occurring between 25 and 35 years of age.

Table 6 shows the parameter estimates and their standard errors obtained when selected covariates of interest were simultaneously fitted to mesothelioma deaths, under multiplicative and additive models. Also, Table 6 reports the estimates for each variable in relation to one of the categories of the variable chosen as reference. A test for the significance of each parameter can be made by comparing the ratio of the parameter to its standard error to a standard normal deviate. Both relative and excess risks were closely related with time since first and last employment, the additive model showing greater estimates. Age at first exposure was inversely related with mesothelioma risk under the multiplicative model, while excess risk showed an elevated risk in subjects aged 35 or older when starting exposure. Duration of employment showed no clear pattern of risk, though the risk estimates were consistently above unity under both models.

Figure 1 reports levels of asbestos dusts in various departments of the factory. In carding, levels as high as $100 \mathrm{ff} \mathrm{cm}^{-3}$ were found in the late $60 \mathrm{~s}$ and as high as $25 \mathrm{ff} \mathrm{cm}^{-3}$ in the early $70 \mathrm{~s}$.

\section{DISCUSSION}

This cohort study of asbestos textile workers found an extremely high SMR of pleural and peritoneal mesothelioma. Increased SMRs were also observed for lung, ovarian, laryngeal and oral and pharyngeal cancers, as well as for all cancer mortality that was 
Table 6 Parameter estimates and their standard errors (s.e.) obtained by fitting selected variables together to risk of mesothelioma (pleural and peritoneal)

\begin{tabular}{|c|c|c|c|c|c|c|c|c|}
\hline Covariate & Observed deaths & Person-years & \multicolumn{3}{|c|}{ Multiplicative model } & \multicolumn{3}{|c|}{ Additive model } \\
\hline Male & 17 & 22332 & - & - & 1.00 & - & - & 1.00 \\
\hline Female & 20 & 30692 & 0.52 & 0.35 & 1.68 & -0.10 & 0.25 & 0.90 \\
\hline \multicolumn{9}{|c|}{ Age at first exposure (years) } \\
\hline$<25$ & 12 & 24269 & - & - & 1.00 & - & - & 1.00 \\
\hline \multicolumn{9}{|c|}{ Duration of employment ${ }^{\mathrm{a}}$ (years) } \\
\hline$<1$ & 7 & 18870 & - & - & 1.00 & - & - & 1.00 \\
\hline to $<5$ & 12 & 16194 & 0.66 & 0.48 & 1.93 & 0.75 & 0.33 & 2.12 \\
\hline$\geqslant 5$ & 18 & 17960 & 0.37 & 0.45 & 1.45 & 0.57 & 0.31 & 1.77 \\
\hline \multicolumn{9}{|c|}{ Time since first employment ${ }^{\mathrm{a}}$ (years) } \\
\hline$<3$ & 2 & 14493 & - & - & 1.00 & - & - & 1.00 \\
\hline 3 to $<15$ & 7 & 20254 & 0.44 & 0.80 & 1.56 & 1.26 & 0.59 & 3.52 \\
\hline$\geqslant 15$ & 28 & 18277 & 1.46 & 0.75 & 4.31 & 3.24 & 0.54 & 25.56 \\
\hline
\end{tabular}

aEstimates from a model including sex, age at first exposure, duration and time since first employment. 'Estimates from a model including sex, age at first exposure, duration and time since last employment. Relative (RR) and absolute excess risks (ER) are given in relation to an arbitrarily selected reference category.

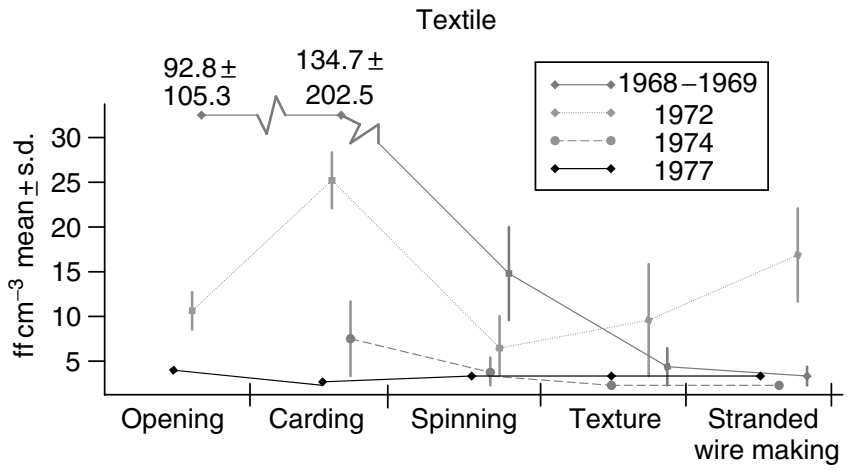

Figure I Level of asbestos exposure in departments in the factory.

approximately twice than expected. Overall, observed deaths were $60 \%$ more than expected, due to excess mortality from cancers but also from other respiratory tract diseases. The large number of deaths from asbestosis testify the magnitude of exposures.

Relative risks of mesothelioma following asbestos exposure have varied widely in previous studies. Two recent cohort studies in Norway and Israel found standardized incidence ratios above 5000 (Tulchinsky et al, 1999; Ulvestad et al, 2002). The risk of developing mesothelioma has been estimated as proportional to a third or fourth power of time since first occupational exposure to asbestos (Peto et al, 1982). In this study, the SMR of mesothelioma was 2780 , and when we considered selected time-related covariates together in a model, latency was the main determinant of mesothelioma risk. There was no significant trend in risk with duration of employment, and also exposures of a few months increased pleural cancer risk. In fact, six out of 23 individuals deceased for pleural cancer had an employment period lower than 1 year, and three of those worked for less than 4 months at the company. We found high relative and absolute risks for a long time since last employment. However, time since first and last employment were highly correlated - due to short duration of exposures reported for several members of this cohort - and it was not possible to consider these variables together to disentangle their separate effects.

These findings are compatible with models of carcinogenesis involving an early stage effect for asbestos exposure (Peto et al, 1982). On the other side, we observed increasing absolute risks with age at first exposure. This may be due to unreported earlier exposures and/or to residual confounding. In any case the excess risk was an order of magnitude lower than that reported for latency.

With reference to other neoplasms, asbestos workers of the textile industry have been reported to experience the highest lung cancer risks, probably because of the stronger carcinogenic effect of long and thin fibres used (Mossman and Gee, 1989; Boffetta, 1998). We found a substantial increase of lung cancer risk $(S M R=282)$, with a direct trend with duration of employment, besides latency. The SMR of lung cancer increased up to 25 years after exposure had ceased, and then declined. As a result, the excess deaths from mesothelioma surpassed those from lung cancer $\geqslant 25$ years after last employment $(9.7 v s 7)$ and $\geqslant 35$ years after first employment (8.8 vs 6.5).

In this study, oro-pharyngeal and laryngeal cancers presented similar results: seven male and no female deaths, and 2.3-fold elevated SMR, comparable to other Italian asbestos-exposed cohorts (Piolatto et al, 1990; Puntoni et al, 2001). Since these findings may simply reflect bias or confounding (Griffiths and Malony, 2003), we computed expected deaths and SMR for male laryngeal cancer also applying Piedmont regional mortality rates, which were available from 1970 but the SMR decreased only slightly, to 213.5. However, an elevated consumption of alcohol and cigarettes in the cohort studied as compared to the general population could not be excluded, since no information was available on these aspects for most subjects. Inferences from 
relative risks of other illnesses are difficult, since smoking and asbestos exposures generally affect the same diseases, that is, those of the respiratory tract. Considering alcohol intake, we used mortality from liver cirrhosis as an indicator of consumption. We observed 19 male deaths from liver cirrhosis, while 14.2 were expected $(S M R=134)$. Further, a potential effect of tobacco and alcohol is supported by the observation that all oro-pharyngeal, laryngeal and liver cancer deaths were among males, and that cigarette smoking has been uncommon among Italian women until recent years (Gallus et al, 2002).

The excess risk of ovarian cancer (five observed deaths, SMR $=261$ ) can be related to the exposure of ovarian epithelium which, like the peritoneum, is exposed to the carcinogenic effect of asbestos (Parazzini et al, 1991).

Intestinal cancers also had increased SMR, but potential misdiagnoses of these cancer sites instead of nearby peritoneal mesothelioma remain possible (Doll and Peto, 1987). Considering the small number of deaths and the weakness of the association, 2-3 mis-diagnosed deaths would be enough to explain the elevated SMR. It should be noted, however, that data from literature do not fully agree on the association between the above cancers, mainly laryngeal, gastrointestinal and ovarian cancer and asbestos exposure (Doll and Peto, 1985; Zheng et al, 1992; Consensus Report, 1997; Rafferty et al, 2001; De la Provote et al, 2002; Griffiths and Malony, 2003).

We found no excess risk of most urogenital tract cancers, particularly of the kidney $(\mathrm{SMR}=98)$ that has been reported as a potential asbestos-related cancer (Smith et al, 1989; Consensus Report, 1997).

The latency period between first asbestos exposure and occurrence of mesothelioma is seldom less than 10 years (Doll and Peto, 1985), while we found that two male subjects had died from pleural cancer only 6 years after first employment. However, both of them reported previous job-related exposures to asbestos. No other pleural cancer and one out of 14 peritoneal cancer cases

\section{REFERENCES}

Baker RJ, Nelder JA (1978) Generalized Linear Interactive Modeling (GLIM) System. Release 3. Numerical Algorithms Group: Oxford

Berry G, Newhouse ML, Wagner JC (2000) Mortality from all cancers of asbestos factory workers in east London 1933-80. Occup Environ Med 57: $782-785$

Bianchi C, Giarelli L, Grandi G, Brollo A, Ramani L, Zuch C (1997) Latency periods in asbestos-related mesothelioma of the pleura. Eur J Cancer Prev 6: $162-166$

Boffetta P (1998) Health effects of asbestos exposure in humans: a quantitative assessment. Med Lav 89: 471-480

Breslow NE, Day NE (1987) Statistical Methods in Cancer Research. Vol II. The Design and Analysis of Cohort Studies. IARC Sci Publs No. 82. IARC, International Agency for Research on Cancer: Lyon

Breslow NE, Lubin JH, Marek P, Langholz B (1983) Multiplicative models and cohort analysis. J Am Stat Assoc 78: 1-12

Cislaghi C, Decarli A, La Vecchia C, Laverda N, Mezzanotte G, Smans M (1986) Dati, Indicatori e Mappe di Mortalità Tumorale. Data, Statistics and Maps of Cancer Mortality. Italia 1975/1977. Pitagora Editrice: Bologna (in Italian)

Consensus Report (1997) Asbestos, asbestosis, and cancer: the Helsinki criteria for diagnosis and attribution. Scand J Work Environ Health 23: $311-316$

de La Provote S, Desoubeaux N, Paris C, Letourneux M, Raffaelli C, Galateau-Salle F, Gignoux M, Launoy G (2002) Incidence of digestive cancers and occupational exposure to asbestos. Eur J Cancer Prev 11: $523-528$

Doll R, Peto J (1985) Effects on Health of Exposure to Asbestos. HMSO: London reported previous occupational exposures. This was of concern, because the analysis on time-related covariates could have been affected. However, duration of employment of the three subjects who died from mesothelioma was less than 1, 3 and 6 years, respectively. One started working at the company at 29 years and two after 35 years of age. Therefore, it is possible that mesothelioma risks for a late age at first exposure could be somewhat overestimated.

Among the strengths of the study are the high number of women included, the originality of the cohort, which included subjects exposed to very high doses of asbestos fibres, and the long followup that allowed to adequately evaluate risk of mesothelioma, that is, a cancer with a long latency period between first asbestos exposure and cancer death.

This study, in conclusion, provides additional quantitative information on the relative risks of pleural and peritoneal mesothelioma (including ovarian cancer) and lung cancer in a cohort of textile workers. The central role of latency and of cumulative exposure in determining, respectively, the risk of mesothelioma and of lung cancer was also assessed. Of specific interest is the over 30 -fold excess risk of pleural cancer even in workers exposed for very short time ( $<1$ year). In fact, exposure in this factory almost approached experimental conditions.

\section{ACKNOWLEDGEMENTS}

This work was conducted with the contribution of the Italian Association for Research on Cancer, Milan, the Italian League Against Cancer and the Italian Ministry of Education (COFIN 2003). Claudio Pelucchi was supported by a fellowship from the Italian Foundation for Cancer Research (FIRC). We thank Ms MP Bonifacino for editorial assistance.
Doll R, Peto J (1987) Other asbestos-related neoplasms. In Asbestos-Related Malignancy Antman K, Aisner J (eds) pp 81 -96. Grune \& Strotton Inc.: Florida

Gallus S, Colombo P, Scarpino V, Zuccaro P, Apolone G, La Vecchia C (2002) Smoking in Italy, 2002. Tumori 88: 453-456

Goodman M, Morgan RW, Ray R, Malloy CD, Zhao K (1999) Cancer in asbestos-exposed occupational cohorts: a meta-analysis. Cancer Causes Control 10: $453-465$

Griffiths H, Malony NC (2003) Does asbestos cause laryngeal cancer? Clin Otolaryngol 28: $177-182$

Hauptmann M, Pohlabeln $\mathrm{H}$, Lubin JH, Jockel KH, Ahrens W, Bruske-Hohlfeld I, Wichmann HE (2002) The exposure-timeresponse relationship between occupational asbestos exposure and lung cancer in two German case-control studies. Am J Ind Med 41: 89-97

Hemminki K, Li X (2003) Mesothelioma incidence seems to have levelled off in Sweden. Int J Cancer 103: 145-146

Hodgson JT, Darnton A (2000) The quantitative risks of mesothelioma and lung cancer in relation to asbestos exposure. Ann Occup Hyg 44: 565-601

ISTAT (1955 - 1996) Annuario Statistico Italiano. ISTAT, Istituto Nazionale di Statistica: Rome

McDonald JC, Liddell FDK, Dufresne A, McDonald AD (1993) The 1891 1920 birth cohort of Quebec chrysotile miners and millers: mortality 1976-88. Br J Ind Med 50: $1073-1081$

Montanaro F, Bray F, Gennaro V, Merler E, Tyczynski JE, Parkin DM, The ENCR working group (2003) Pleural mesothelioma incidence in Europe: evidence of some deceleration in the increasing trends. Cancer Causes Control 14: $791-803$

Mossman BT, Gee JB (1989) Asbestos-related diseases. New Engl J Med. 320: $1721-1730$ 
Newhouse ML, Berry G (1979) Patterns of mortality in asbestos factory workers in London. Ann NY Acad Sci 330: 53-60

Parazzini F, Franceschi S, La Vecchia C, Fasoli M (1991) The epidemiology of ovarian cancer. Gynecol Oncol 43: 9-23

Pelucchi C, Malvezzi M, La Vecchia C, Levi F, Decarli A, Negri E (2004) Mesothelioma epidemic in Western Europe: an update. Br J Cancer 90: $1022-1024$

Peto J, Decarli A, La Vecchia C, Levi F, Negri E (1999) The European mesothelioma epidemic. Br J Cancer 79: 666-672

Peto J, Seidman H, Selikoff IJ (1982) Mesothelioma mortality in asbestos workers: implications for models of carcinogenesis and risk assessment. Br J Cancer 45: 124-135

Piolatto PG, Negri E, La Vecchia C, Pira E, Decarli A, Peto J (1990) An update of cancer mortality among chrysotile asbestos miners in Balangero, northern Italy. $\mathrm{Br} J$ Ind Med 47: 810-814

Puntoni R, Merlo F, Borsa L, Reggiardo G, Garrone E, Ceppi M (2001) A historical cohort mortality study among shipyard workers in Genoa, Italy. Am J Ind Med 40: 363-370

Rafferty MA, Fenton JE, Jones AS (2001) The history, aetiology and epidemiology of laryngeal carcinoma. Clin Otolaryngol 26: $442-446$

Saracci R (1977) Asbestos and lung cancer: an analysis of the epidemiological evidence on the asbestos-smoking interaction. Int $J$ Cancer 20: 323-331
Scansetti G, Piolatto PG, Pira E (1985) Il Rischio da Amianto Oggi. Regione Piemonte: Torino

Selikoff IJ, Hammond EC, Seidman H (1979) Mortality experience of insulation workers in the United States and Canada, 1943-1976. Ann NY Acad Sci 330: $91-116$

Smith AH, Shearn VI, Wood R (1989) Asbestos and kidney cancer: the evidence supports a causal association. Am J Ind Med 16: 159-166

Tulchinsky TH, Ginsberg GM, Iscovich J, Shihab S, Fischbein A, Richter ED (1999) Cancer in ex-asbestos cement workers in Israel, 1953-1992. Am J Ind Med 35: 1-8

Ulvestad B, Kjaerheim K, Martinsen JI, Damberg G, Wannag A, Mowe G, Andersen A (2002) Cancer incidence among workers in the asbestoscement producing industry in Norway. Scand J Work Environ Health 28: $411-417$

Vainio H, Boffetta P (1994) Mechanisms of the combined effect of asbestos and smoking in the etiology of lung cancer. Scand J Work Environ Health 20: $235-242$

Yano E, Wang ZM, Wang XR, Wang MZ, Lan YJ (2001) Cancer mortality among workers exposed to amphibole-free chrysotile asbestos. Am J Epidemiol 154: 538-543

Zheng W, Blot WJ, Shu XO, Diamond EL, Gao YT, Ji BT, Fraumeni Jr JF (1992) Risk factors for oral and pharyngeal cancer in Shanghai, with emphasis on diet. Cancer Epidemiol Biomarkers Prev 1: $441-448$ 